\title{
A Neo-Kohlbergian Approach to Morality Research
}

JAMES R. REST

1941-1999, Department of Educational Psychology, University of Minnesota, USA

\section{DARCIA NARVAEZ}

Department of Psychology, University of Notre Dame, USA

\section{STEPHEN J. THOMA}

Department of Human Development, University of Alabama, USA

\section{MURIEL J. BEBEAU}

Department of Preventive Science, School of Dentistry, University of Minnesota, USA

All authors are affiliated with the Center for the Study of Ethical Development, University of Minnesota

ABSTRACT Kohlberg's work in moral judgement has been criticised by many philosophers and psychologists. Building on Kohlberg's core assumptions, we propose a model of moral judgement (hereafter the neo-Kohlbergian approach) that addresses these concerns. Using 25 years of data gathered with the Defining Issues Test (DIT), we present an overview of Minnesota's neo-Kohlbergian approach, using Kohlberg's basic starting points, ideas from Cognitive Science (especially schema theory), and developments in moral philosophy.

\section{Kohlberg's Legacy}

Foremost in Larry Kohlberg's legacy is his modelling of openness to new developments and possibilities. When he was first formulating his theory of moral development, the work of Jean Piaget was coming to the attention of American psychologists (e.g. Flavell, 1963), and the work of John Rawls in moral philosophy (1971) was recognised as a new way for moral philosophy to say something significant (beyond clarifying moral language) about normative ethics. Kohlberg's fusion of Piaget and Rawls excited many researchers because of its interdisciplinary approach (taking seriously the questions and contributions of developmental psychology and of normative ethics), and because it addressed issues of the day (e.g. what is social justice?). Recall that in the 1960s and 1970s the US Civil Rights movement, the Vietnam War and the Watergate Scandal were all controversial issues that divided 
American society. Kohlberg offered a perspective that drew upon the most current work in psychology and philosophy, yet addressed these timely issues.

Kohlberg's ideas dominated the agenda of morality research for decades. In a recent analysis of Kohlberg's writings, Reed (1997) shows that Kohlberg was not particularly concerned with logical consistency among his many projects. Reed contends that Kohlberg's early ventures into moral education, based on a cognitive model of individual moral development (the Six Stage Theory), was not consistent with his later approach, which emphasised the development of community norms (the "Just Community"). Moreover, Kohlberg changed and modified his proposals for a theory of development as he went along: he changed his scoring system of stages throughout the 1970 s and 1980s; in various ways he tried to relate "care" to "justice", and his debates with the Social Learning Theorists (e.g. Kohlberg, 1969) had many vicissitudes. Kohlberg's ideas were in constant flux. As he once confided, he was a moving target and considered himself as his own major revisionist. Therefore it would be a mistake to use his 1981 and 1984 books as the final word on a Kohlbergian approach. One wonders how Kohlberg would have changed his theory, given another decade and a normal life span.

With the benefit of hindsight, with decades of new developments in psychology and philosophy, it remains for others to decide which of Kohlberg's many ideas have turned out to be fruitful. In this article, we audaciously set out to do this and to propose some new ideas, realising, with Kohlberg, that this is an ongoing enterprise, open to revision, and likely to change.

\section{A Neo-Kohlbergian Viewpoint}

Several factors bring us to our discussion. After 25 years of data collection, we have completed a full generation of research with the Defining Issues Test (hereafter referred to as the DIT). Advances in personal computers and technology make possible analyses that heretofore were impractical (e.g. sample sizes of 50,000). Further, the field of morality research has been fragmented and not dominated by any one approach - therefore we feel free to explore theory and research that do not employ a standard approach. In addition, the fields of psychology and philosophy are moving in directions especially congenial to our research. Much of our activity until 1997 is summarised in a recent book, Postconventional Moral Thinking: a neo-Kohlbergian approach (Rest et al., 1999).

We follow Kohlberg's approach to conceptualising moral judgement (see Rest et al., 1999, for fuller discussion). (a) Like Kohlberg, our starting point emphasises cognition. Kohlberg realised there were many starting points for morality research (for instance, one might start out emphasising an evolutionary biosocial perspective, and investigate certain emotions such as empathy, altruism, guilt and shame; or one might focus on the young infant's acquisition of prosocial behaviour). Everyone must begin somewhere, making assumptions and emphasising some things over other things. Despite the limitations of any starting point, the crucial question is, "Having started there, where did it lead? What important phenomena have been illuminated?" (b) Like Kohlberg, we highlight the personal construction of basic 
epistemological categories (e.g. "rights", "duty", "justice", "social order", "reciprocity"). This is not to deny the contribution that cultural ideologies make. Ideologies are group-derived, tools and practices of a culture. We, however, focus on the individual's attempt to make sense of his/her own social experience. (c) We portray change over time in terms of development (i.e. it is possible to talk not only of differences in moral orientation, but also of cognitive "advance" in which "higher is better" in a philosophical, normative-ethical sense). Finally, (d) we characterise the developmental change of adolescents and adults in terms of a shift from conventional to postconventional moral thinking (we think there is a sequence rather than Turiel's notion [e.g. 1983] of these being separate domains). We think these four ideas are the core assumptions of Kohlberg's "cognitive-developmental" approach. This is the Kohlbergian part of our neo-Kohlbergian approach. Because these ideas have been much discussed previously (e.g. Kohlberg, 1969, 1981, 1984, 1986; Colby et al., 1983, 1987), we will not elaborate on them here.

\section{Philosophers' Criticisms of Kohlberg}

Over the past decades, there have been major developments in moral philosophy (e.g. DeGrazia, 1992; Beauchamp \& Childress, 1994; Rest et al., 1999, Chapter 2), including the abandonment of the view that morality is primarily based on a Foundational Principle. In Kohlberg's time-in the 1960s and 1970s-many understood the business of moral philosophy as that of defining and defending the Foundational Principle of morality (be it utilitarian, or deontological, or some mix of principles, etc.). It was assumed that settling on the Foundational Principle (e.g. greatest good for the greatest number, the Categorical Imperative, Rawls's Two Principles of Justice, etc.) would provide the key for solving deductively all moral problems. Accordingly, the main job of the theoretical philosopher was to define the key Foundational Principle. The job of the applied philosopher was to articulate its application to specific cases. The job of the moral educator was to enable people to know and use this key principle in their daily lives.

However, philosophers-whom we suppose are rational, fair-minded and autonomous people-have not been able to agree on the Foundational Principle. The experience of Stephen Toulmin (1981) is instructive. Toulmin, an American bioethicist, was appointed to serve on the US National Commission for the Protection of Human Subjects along with 10 other appointees. Their job was to adopt guidelines for the use of humans in research for the US government. The 11 commissioners found that they could reach consensus on moral judgements about specific cases, but they could not agree on which abstract principles justified their judgements of specific cases. Toulmin challenged the notion that morality proceeds "top-down", from abstract principles applied to specific cases. Rather, he argued, morality is fashioned like common law by people reflecting on specific cases, reaching agreement on specific cases, then analysing similar cases to the paradigm cases, building up a "common morality" as the logical interconnections among cases are established.

Walzer (1983) presents a theoretical account of the view that morality is not 
based on a Foundational Principle but, rather, the morality of a community is gradually built up from the specific experiences of the community in dealing with specific cases. Walzer describes the growth of "common morality" in particular historical communities (e.g. Athens in 5 BC, and the medieval Jewish communities in Europe). Walzer describes how each community faced different moral problems, provided different services for different clienteles, had different organisational apparatuses to deal with problems, raised money in different ways, and conceptualised the practices differently in their moral ideologies. Thus, Walzer argues, the development of morality is not to be understood as an individual's applying a Foundational Principle, but rather the community's reaching agreement about how best to fulfill shareable moral ideals to suit the circumstances.

With these developments in moral philosophy, we can begin to appreciate the difficulties that philosophers have with Kohlberg's definition of Stage 6. The Kohlbergian view of Six Stages is criticised as assuming Foundational Principlism, as deductivistic rather than inductivistic, as too individually orientated rather than community-orientated, as assuming consensus for deontic principles where there is no consensus, for criticising relativism when the assumption of universality is unwarranted, and for assuming that abstract principles provide sufficient guidance for making specific moral decisions (see discussion in Rest et al., 1999).

In addition, Kohlberg is criticised for not having a fully comprehensive theory of morality or moral development (focusing on justice; using a few unrepresentative hypothetical dilemmas; emphasising rational aspects of morality while neglecting emotional aspects; claiming universality on the basis of studying a very limited sector of humanity, etc.). In his later writings, Kohlberg acknowledged the limited scope of his theory and investigations, that his theory starts out with assumptions-just as all theories must start out with limited starting points - and acknowledged that additional constructs and variables were necessary to explain the multitudinous phenomena of morality (Kohlberg, 1986, pp. 499-500). And so the criticism-Kohlberg did not tell us everything about morality - is not really a telling criticism about a theory with an acknowledged limited scope (see Rest et al., 1999).

\section{Differences with Kohlberg's Theory of Six Stages}

We use the term moral schemas (discussed below), rather than moral stages, to signal differences with Kohlberg's conception of "hard" moral stages. Our view of the cognitive structures of moral judgement differ from Kohlberg's stages in the following five ways (the points are not discrete points but are all interconnected):

(a) "Hard" stages versus "soft" stages. We differ with Kohlberg on the concept of "stage"; we envision development as shifting distributions rather than as a staircase. Like Siegler (1997), we believe that development is a matter of changes in the frequency of usage, moving from the less to the more complex.

(b) More specific and concrete. Our schemas are more concrete than Kohlberg's stages (but are more abstract than the typical schemas of Social Cognition 
(e.g. person schemas, role schemas). Our schemas are conceptions of institutions and role-systems in society, whereas Kohlberg regards social institutions as "content". In other words, we have three ways of drawing the distinction between content and structure: Kohlberg's, the neo-Kohlbergian approach in the DIT and Social Cognition. All distinguish general cognitive structure from the content instantiations that can exemplify the structure, but the three draw the distinction at different levels of abstraction.

(c) Cognitive operations and the content-output of operations. Instead of Kohlberg's claim of studying "justice operations", we do not claim that our schemas directly assess cognitive operations. The Colby-Kohlberg scoring system (Colby et al., 1987) explains how one must radically purge content from structure in order to assess the operations of moral thinking. Kohlberg spent the last decade of his life working on the 1987 scoring system to radically purge content from structure. He seems to have assumed that the more abstract the analysis, the more pure the assessment of operations. In contrast, Cognitive Science has not been so eager to purge all content from structure. Gazzaniga et al. (1998) stated that mental operations are the most elusive aspect of cognitive assessment:

A vast amount of research in cognitive science clearly shows we are conscious only of the content of our mental life, not what generates the content. It is the products of mnemonic processing, of perceptual processing, of imaging, that we are aware of-not what produced the products. Sometimes people report on what they think were the processes, but they are reporting after the fact on what they thought they did to produce the content of their consciousness (p. 532).

(d) Universality. Kohlberg postulated universality as a characteristic of stages whereas we regard cross-cultural similarity as an empirical question. He saw a universalistic morality as the bulwark against moral relativism in which a Nazi officer could defend his role in the Holocaust as simply following the relativist norms of his group. In contrast, recent moral philosophers (e.g. Beauchamp \& Childress, 1994; Walzer, 1983) consider "Common Morality" as a community enterprise, relative to situation and circumstance (akin to the development of common law). According to this view, morality is a social construction, evolving from the community's experiences, particular institutional arrangements, deliberations, and the aspirations that are voiced at the time and which win the support of the community. Morality that is relative to group deliberation is not tantamount to the mindless moral relativism or moral scepticism that Kohlberg feared, nor does it pave the way to Nazi atrocities. Common morality might be different for different communities (and therefore relative), but the common morality is debated and scrutinized by members of the community and reflects an equilibrium between the ideals and the moral intuitions of the community. 
(e) Articulation (interviewing task) versus tacit knowledge (multiple choice task). A common assumption in the field of morality, and one with which we disagree, is that reliable information about the inner processes that underlie moral behaviour is obtained only by asking people to explain their moral judgements. Contrary to assuming the face validity of interviews, researchers in Cognitive Science and Social Cognition contend that self-reported explanations of one's own cognitive processes have severe limitations (e.g. Nisbett \& Wilson, 1977; Uleman \& Bargh, 1989). People can report on the products of cognition but not on the mental operations they used to arrive at the product. A large body of research calls into question the privileged place of interview data, dependent on conscious understanding, over recognition data, dependent on implicit understanding.

By requiring participants in research to construct verbal arguments for their moral choices, and to credit someone only with cognition that they can articulate and defend, Kohlberg placed a verbal constraint that credited people with only understanding what they could explain. We believe that this is one reason why there is so little empirical evidence for Stage 5 and 6 reasoning using Kohlberg's scoring system. One advantage of the recognition task of the DIT is that postconventional thinking is not so rarely scored as in the Kohlberg interview.

\section{Developmental Schemas Instead of Stages}

We postulate three structures in moral thinking development: the Personal Interest schema (which derives from Kohlberg's Stage 2 and 3, referred to henceforth as "S23"); the Maintaining Norms schema (deriving from Kohlberg's Stage 4, referred to as "S4"); and the Postconventional schema (deriving from Kohlberg's Stage 5 and 6, referred to as "S56").

Developmentally, a large social-cognitive advance in adolescence (the youngest group that we study with the DIT) is the "discovery of society" - that is, that people in society are related to each other through institutions, established practices, role-systems ("the system"), and not only on a face-to-face basis (as with kin, friends, well-known acquaintances). Not only does Kohlberg speak of this development (attaining a sociocentric perspective) in adolescence (1984), but others do also (e.g. Adelson, 1971; Youniss \& Yates, 1997). Awareness that society is organised in terms of a system of rules, roles and institutions raises questions about the morality of society and questions of moral authority. (How does one organise a network of co-operation on a society-wide basis, where there is full reciprocity and mutual benefit? How are power, wealth and opportunity to be distributed? What is the legitimate use of force?) These are the issues of "macro-morality" as distinct from issues of "micro-morality" (i.e. how a person interacts with others in everyday face-to-face situations). In our view, the three moral schemas are developmentally ordered ways of answering the "macro" question (how to get along with people who are not friends, kin or personal acquaintances, i.e. how to organise society-wide co-operation). 


\section{Personal Interest Schema}

We suppose that the Personal Interest schema develops in childhood and that by the time participants have sufficient reading ability to take the DIT (i.e. have a 12 year-old reading level), this schema is no longer central in their thinking. The Personal Interest schema does not entail a sociocentric perspective. Questions addressing societal co-operation are answered as if there were only "micro-moral" relationships to consider. Individuals using the Personal Interest schema analyse what each stakeholder in a moral dilemma has to gain and lose as if they did not have to worry about organising co-operation on a society-wide basis. The "Personal Interest" schema justifies a decision as morally right by appealing to the personal stake the actor has in the consequences of an action. The Personal Interest schema includes individual prudential concerns and concerns for those with whom one has an affectionate relationship. Thus it has elements described by Kohlbergian Stages 2 and 3 because the two elements fuse together as a single factor in DIT data. In DIT data, both Stage 2 and Stage 3 items are regarded as more primitive forms of thinking - see factor analysis results, discussed in Rest et al., 1999). On the whole, DIT research cannot offer insight into development in childhood, or into the distinctions within the Personal Interest schema.

\section{The Maintaining Norms Schema}

We suppose that the Maintaining Norms schema is developmentally more advanced in attaining a sociocentric perspective (one has to consider how people who are not friends, kin or well-known acquaintances are going to co-operate). With the Maintaining Norms schema, the individual is able to identify the established practice (the existing rules and roles) and who are the de facto authorities. Functionally, the Maintaining Norms schema is a prevalent first solution to conceptualising societywide co-operation. Examples include Kohlberg's "Law and Order" stage (1984) and Richard Nixon's "Silent Majority"; McClosky and Brill (1983) talk about the "Conservative" orientation; Adelson (1971) talked about the "Authoritarianism" of adolescence. Common to all of these, the Maintaining Norms schema has the following elements. (a) The perceived need for generally accepted social norms to govern a collective. (b) The necessity that the norms apply society-wide, to all people in a society. (c) The need for the norms to be clear, uniform, and categorical (that there is "the rule of law.") (d) The norms are seen as establishing a reciprocity (each citizen obeys the law, expecting that others will also obey). (e) The establishment of hierarchical role structures, of chains of command, of authority and duty. That is, in an organised society, there are hierarchical role structures (e.g. teacherpupil, parent-child, general-soldier, doctor-patient, etc.). One must obey authorities, not necessarily out of respect for the personal qualities of the authority, but out of respect for the social system.

For the Maintaining Norms schema, maintaining the established social order defines morality. In the Maintaining Norms schema, "law" is connected to "order" in a moral sense. The schema leads to the expectation that without law (and duty 
to one's roles), there would be no order, people would instead act on their own special interests, leading to anarchy-a situation that responsible people want to prevent. For this schema, no further rationale for defining morality is necessary beyond simply asserting that an act is prescribed by the law, is the established way of doing things, or is the established Will of God. The schema, Maintaining Norms, is consonant with "Legal Positivism" (Hart, 1961, pp. 181-182, 253-254) in the sense that neither appeals to moral criteria beyond the law itself. Acquisition of this schema is what gives Conventional thinkers their sense of moral necessity for the maintenance of social order. In other words, the schema provides a sense of moral certainty ("I know I'm right for the sake of our entire society") and therefore fuels the special zeal of conventional thinkers.

\section{Postconventional Schema}

Essential to postconventional thinking is that moral obligations are to be based on shared ideals, are fully reciprocal, and are open to scrutiny (i.e. subject to tests of logical consistency, experience of the community and coherence with accepted practice). Over the centuries, philosophers have proposed many visions for a society based on moral ideals (e.g. utilitarian, social contract, virtue-based, feminist, casuist, religious ideals). Not all moral theories fit our criteria of Postconventional schema: (a) emotivist theories of morality say that morality is nothing but the personal expression of approval or disapproval (e.g. Stevenson, 1937); (b) Nietzsche [e.g. 1886/1968] regarded co-operation as a bad idea and a ploy of the weak to hold down the strong; and (c) ethical approaches based on Fundamentalist/Orthodox religious views deny that their version of God's Will is open to scrutiny (see Beauchamp \& Childress, 1994, for a discussion of the relative adequacy of various moral theories.) However, most modern moral philosophies do fit our notion of postconventionality. They are based on ideals, the ideals are shareable, are open to debate and tests of logical consistency, and so on. Whereas Kohlberg was partisan to the neo-Kantian, deontological theory of John Rawls (1971), we attempt to side-step the current disputes of moral philosophy by adopting a looser, broader (less daring, more tepid) notion of cognitive advance. Instead of Kohlberg's definition of Stage 6 (in which the individual's cognitive operations achieve "ideal reciprocity", striking similarities to the theory of John Rawls), our definition of the Postconventional schema is not partial to any particular moral philosopher. Four elements comprise the Postconventional schema: primacy of moral criteria, appeal to an ideal, shareable ideals and full reciprocity (discussed in Rest et al., 1999, Ch. 3).

There has been, and still is, much dispute among moral philosophers about what ideals should govern society, how to optimise all the participants' welfare, who is a participant, what "fair-minded" and "impartial" mean, what "rational" and "equal" mean, what constitutes "logical coherence", and the relative importance of principles and paradigm cases. These issues are the unsettled business of much of current moral philosophy. Nevertheless, we focus on the gulf between conventionality and postconventionality (what Kohlberg regarded as the distinction between Stage 4 and Stage 5-Colby et al., 1987, Vol. 1, pp. 28-29). This gulf is what 
polarises people on so many public policy issues (e.g. rights of homosexuals, religion in public schools, euthanasia, abortion, women's roles, etc.), fuels the "Culture Wars" (Orthodoxy versus Progressivism: Hunter, 1991), and is the most important clash in ideology since the Cold War (religious fundamentalism versus secular modernism: see Marty \& Appleby, 1993).

Like Kohlberg, we affirm a developmental progression from conventionality to postconventionality. A major difference between the Maintaining Norms schema and the Postconventional schema is how each attempts to establish a moral consensus: the strategy of the Maintaining Norms schema is to gain consensus by appealing to established practice and existing authority. In contrast, the strategy of the Postconventional schema is to gain consensus by appealing to ideals and logical coherence. Like Kohlberg, we assert not only that there are different cognitive structures for moral judgement, but also that they are developmentally ordered-the Postconventional schema is more advanced (in a normative ethical sense) than the Maintaining Norms schema. The cognitive developmental distinction, however, is not the same thing as the distinction in political ideology between the right-wing and left-wing. It is possible to be conventional left-wing (e.g. Political Correctness) as well as conventional right-wing (George Wallace's Law and Order). It is possible to be postconventional left-wing (Rawls, 1971, 1993) and postconventional Conservative (e.g. Sandel, 1982), Communitarian (Walzer, 1983) or Libertarian (Nozick, 1974).

\section{The Relation of Schemas to Measuring Moral Judgement}

Schemas are general knowledge structures residing in long-term memory (see, for example, Rummelhart, 1980; Taylor \& Crocker, 1981). Schemas (expectations, hypotheses, concepts) are formed as people notice similarities and recurrences in experiences. A schema consists of a representation of some prior stimulus phenomenon and is used to interpret new information (sometimes referred to as "top-down" processing). Schemas are evoked (or "activated") by current stimulus configurations that resemble previous stimuli. The functions of schemas are essential to human understanding. For example, schemas fill in information where information is scarce or ambiguous, provide guidance for evaluating information and for problem-solving. In short, schemas facilitate information processing.

The DIT is a device for activating moral schemas. Reading moral dilemmas and the DIT issue statements activates moral schemas (to the extent that a person has developed them). The items of the DIT are fragments of lines of reasoning; the items are not complete orations arguing for one course of action or another. (The items are often in the form of questions, without advocating one course of action or another.) The items balance "bottom-up" processing (stating just enough of a line of argument for understanding) with "top-down" processing (stating not too much of a line of argument so that the participant has to "fill in" the meaning from schemas already in long-term memory). As the participant encounters a DIT item that both makes sense and also activates a preferred schema, that item is given a high rating and ranked as being of high importance. Alternatively, when the participant 
encounters an item that either does not make sense or seems simplistic and unconvincing (is not activating a preferred schema), the item receives a low rating. In a sense, the DIT is a "projective test" in that the fragmented nature of the items requires the participant to supply meaning to the items that they are rating. By the patterns of ratings and rankings, we arrive at estimates of the relative strength of the three schemas.

\section{Measuring Moral Judgement with the DIT}

The book, Postconventional Moral Thinking (Rest et al., 1999, Ch. 4) is devoted to citing the literature on moral judgement using the DIT, consisting of over 400 published articles plus a considerable number of studies that are not published supporting seven validity and reliability criteria. Here, we highlight our general strategy for establishing validity and give brief conclusions.

The seven criteria operationalise what we mean by "construct validity" for a test of moral judgement. That is, these criteria set forth what we believe a measure of moral judgement development must demonstrate to be viable. The seven criteria are as follows: (1) differentiation of various age/education groups; (2) longitudinal gains; (3) correlation with cognitive capacity measures; (4) sensitivity to moral education interventions; (5) correlation with behaviour and professional decision making; (6) predicting to political choice and attitude; and (7) reliability. Briefly, here are the conclusions from Rest et al. (1999, Ch. 4):

1. Differentiation of various ageleducation groups. Studies of large composite samples (thousands of subjects) show that $30-50 \%$ of the variance of DIT scores is attributable to level of education in samples ranging from juniorhigh education to PhDs.

2. Longitudinal gains. A 10-year longitudinal study shows significant gains of men and women, of college-attenders and people not attending college, from diverse walks of life. A review of a dozen studies of freshman to senior students in liberal arts colleges $(n=755)$ shows effect sizes of 0.80 ("large" gains). DIT gains are one of the most dramatic longitudinal gains in college of any variable studied in college students.

3. DIT scores are significantly related to cognitive capacity measures of moral comprehension $(r=0.60 \mathrm{~s})$, to recall and reconstruction of postconventional moral argument (Narvaez, 1998, 1999), to Kohlberg's measure and (to a lesser degree) to other cognitive developmental measures.

4. DIT scores are sensitive to moral education interventions. One review of over 50 intervention studies reports an effect size for dilemma discussion interventions to be 0.41 ("moderate" gains), whereas the effect size for comparison groups was only 0.09 ("small" gains).

5. DIT scores are significantly linked to many "prosocial" behaviours and to desired professional decision making. One review reports that 32 of 47 measures were statistically significant. Chapters in Rest and Narvaez (1994) link DIT scores to many aspects of professional decision making. 
6. DIT scores are significantly linked to political attitudes and political choices - in a review of several dozen correlates with political attitude, DIT scores typically correlate in the range, $r=0.40-0.65$. When combined in multiple regression with measures of cultural ideology, the combination predicts up to two-thirds of the variance in opinions about controversial public policy issues (such as abortion, religion in the public school, women's roles, rights of the accused, rights of homosexuals, free speech issues). Because such issues are among the most hotly debated issues of our time, the DIT's predictability to these issues is a phenomenon of importance.

7. Reliability. Cronbach's alpha is in the upper $0.70 \mathrm{~s} / \mathrm{low} 0.80 \mathrm{~s}$. Test-retest is about the same. In short, reliability is adequate.

Furthermore, DIT scores show discriminant validity from verbal ability/general intelligence and from conservative/liberal political attitudes (see review of more than 20 studies in Thoma et al., 1999). That is, the information in DIT scores predict to the seven validity criteria above and beyond that accounted for by scores of verbal ability/general intelligence or political attitude. Moreover, the DIT is equally valid for males and females. Sex (gender) accounts for less than one half of a per cent of the variance of the DIT, whereas education is 250 times more powerful in predicting DIT variance (Thoma, 1986).

Moreover, several developments have been made recently that increase the power of the validity trends. (a) We have devised a new developmental index for the DIT (N2 to replace the $P$ index-Rest et al., 1999, 2000). (b) We have devised a new way to check for the reliability of data in a questionnaire (i.e. whether or not a participant is giving bogus data) (Rest et al., 1999). (c) We have completed preliminary testing of a new version of the DIT ("DIT2") with new dilemmas and new items that is more updated (Heinz is retired from active duty), is shorter, has clearer instructions, purges fewer subjects for bogus data, and is slightly more powerful on validity criteria. DIT2 indicates that new stories and items can be devised in place of the old "DIT1".

\section{Moving Beyond Moral Judgement Per Se}

In the early 1970s, the DIT started out as a "quick and dirty" alternative to the arduous Kohlberg interview. The DIT was group-administered, multiple-choice and mechanically scored. As research began to accumulate, as the DIT provided consistent and reliable trends in moral judgement development, some of us began to think that the DIT was more than only "quick and dirty".

Recently, we have discovered that more variables can be derived from DIT data than moral judgement (measured by the $P$ score and $\mathrm{N} 2$ index). In addition to tapping moral judgement development, we can regard the DIT as an information processing task. The general idea is that some people have an easier time making moral judgements than others; some people are more certain of their judgements, are more consistent and seem to approach the task of handling moral dilemmas with a definite and coherent point-of-view. What we find (Rest et al., 2000) is that the 
more consolidated a person is in one of the schemas we have defined (Personal Interest, Maintaining Norms or Postconventional), the greater the ease and consistency in information processing. Conversely, the greater the mix of schemas (bits and pieces of all the schemas, but not a consistent point-of-view), the more difficulty the person has in making a decision and being consistent across tasks. In other words, the schemas predict performance on the information processing variables. This links our particular definitions of moral schemas with specific effects, and thus bolsters the claim that we have defined the operative structures in people's moral thinking (otherwise, our measures of consolidation and schema predominance would have produced a meaningless jumble of numbers).

Whereas consolidation and predominance in any one schema (S23, S4 or S56) predicted ease and consistency in information processing (the schemas are alike in this regard), we also find that the different moral schemas lead to drastic differences in decision-making. In other words, while S4 and S56 are alike in leading to ease of information processing, they are different in terms of where they lead. For instance, S56 favours rights of homosexuals, S4 tends not to; S56 favours abortion rights, S4 does not. In general, S56 tends to endorse political liberal ideology; S4 tends to endorse more conservative political ideology and more religious orthodoxy.

With clearer notions about what moral judgement is, we are clearer about what moral judgement is not. Clearly in the psychology of morality, there are many variables and constructs besides moral judgement schemas (or what can be measured by the DIT). Various discussions of the multifaceted nature of morality have been written (Rest, 1983; Thoma, 1994; Narvaez \& Rest, 1995; Bebeau et al., 1999). Here we will mention just two new directions that go beyond the DIT and global moral judgement schemas.

1. Intermediate constructs. Moral judgement, as studied in the Kohlbergian tradition, concerns people's conceptions about the morality of society at a global, coarse-grained, abstract level. From this highly abstract level, one may not be able to deduce solutions for problems in specific contexts. When people make moral decisions about moral dilemmas in their lives, they use concepts at a more "intermediate" level; constructs such as "due process", "informed consent", "patient-autonomy", "standards of evidence", "confidentiality", "intellectual freedom". These are often the conceptual tools emphasised in courses on professional ethics. Bebeau and Thoma (1998, 1999) identify concepts at the intermediate level of abstraction, and discuss educational programmes to instruct students in their use.

2. Theme comprehension in moral texts. Narvaez (1999) and Narvaez et al. (1998, 1999) merge traditional moral judgement research strategies with text comprehension research methods to illuminate the comprehension of moral themes in stories. Moral educators commonly assume that children understand the moral messages of moral stories, and that reading moral stories leads to moral literacy which in turn leads to moral character (Bennett, 1993). Narvaez and colleagues have found that young children do not understand the intended messages, and that there is a developmental trend 
in understanding beyond what can be explained by reading comprehension ability. Moral text comprehension offers a method of assessing moral cognition other than the DIT or Kohlberg's interview method.

\section{Conclusion}

Kohlberg's ideas stimulated much research over past decades, including the development of the DIT. With 25 years of DIT research, we are able to make particular claims with some certainty. Spurred by developments in psychology and philosophy, we have moved the moral judgement enterprise towards a more complex view of moral judgement and comprehension. Our interpretations of the findings form the basis of our neo-Kohlbergian viewpoint.

Correspondence: Dr Darcia Narvaez, Department of Psychology, Haggar Hall, University of Notre Dame, South Bend IN, USA; e-mail: dnarvaez@nd.edu.

\section{NOTE}

[1] Current research papers of Center staff (recently published, in press, submitted, and in-house) are listed in a free "Information Pack" available from the Center by calling (from within N. America) 6126240876 or writing to: The Center for the Study of Ethical Development University of Minnesota, 206 Burton Hall, 178 Phillsbury Dr SE, MPLS, MN 55455, 48A, or see our website: $<$ http://edpsy.coled.umn.edu/psychf/csed $>$. Also available is information about ordering printed, optical scan sheets of the DIT (and DIT2) with the computerized Scoring Service. Researchers who have used the DIT and the Minnesota's Center Scoring Service in the past can return the scoring diskette for reanalysis for all the new variables (now about 50 variables per questionnaire) at no cost. An in-house booklet, Exploring Moral, Fudgement (Rest et al., 1999) illustrates the procedures for using scored data, importing data into a statistical package, designing new dilemmas and indexes, and provides a tutorial on floppy diskette.

\section{REFERENCES}

Adelson, J. (1971) The political imagination of the young adolescent, Daedalus, 100, 1013-1050.

Beauchamp, T.L. \& Childress, J.F. (1994) Principles of Biomedical Ethics, 4th edn. (New York, Oxford University Press).

Bebeau, M.J. \& Thoma, S.J. (1998) Designing and testing a measure of intermediate level ethical concepts, paper presented at the annual meeting of the American Educational Research Association, San Diego, CA, 13-17 April.

Bebeau, M.J. \& Thoma, S.J. (1999) "Intermediate concepts" and the connection to moral education, Educational Psychology Review, 11, pp. 343-360.

Bebeau, M.J., Rest, J. \& Narvaez, D. (1999) Moving beyond the promise: a perspective for research in moral education, Educational Researcher, 28, pp. 18-26.

BennetT, W. (1993) The Book of Virtues (New York, Simon \& Schuster).

Colby, A., Kohlberg, L., Gibbs, J. \& Lieberman, M. (1983) A longitudinal study of moral judgment, Society for Research in Child Development: Monograph Series, 48, no. 4, Chicago. 
Colby, A., Kohlberg, L., Speicher, B. et al. (1987) The Measurement of Moral fudgment, vols 1 and 2 (New York, Cambridge University Press).

DeGrazia, D. (1992) Moving forward in bioethical theory: theories, cases, and specified principlism, Fournal of Medicine and Philosophy, 17, pp. 511-539.

Flavell, J.H. (1963) The Developmental Psychology of fean Piaget (Princeton, NJ, VanNostrand).

Gazzaniga, M.S., Ivry, R.B. \& Mangun, G.R. (1998) Cognitive Neuroscience: the biology of the mind (New York, Norton).

HaRT, H.L.A. (1961) The Concept of Law (London, Oxford University Press).

Hunter, J.D. (1991) Culture Wars: the struggle to define America (New York, Basic Books).

KoHLBERG, L. (1969) Stage and sequence: the cognitive developmental approach to socialization, in:

D.A. GosLin (Ed.) Handbook of Socialization Theory, pp. 347-480 (Chicago, Rand McNally).

Kohlberg, L. (1981) Essays on Moral Development, vol. 1: The Philosophy of Moral Development (New York, Harper \& Row).

KohlBerg, L. (1984) Essays on Moral Development: the nature and validity of moral stages, vol. 2 (San Francisco, Harper \& Row).

Kohlberg, L. (1986) A current statement on some theoretical issues, in: S. ModgIL \& C. ModgIL (Eds.) Lawrence Kohlberg: consensus and controversy, pp. 485-546 (Philadelphia, Falmer Press).

Marty, M.E. \& Appleby, R.S. (Eds) (1993) Fundamentalism and the State (Chicago, University of Chicago).

McClosky, H. \& BRill, A. (1983) Dimensions of Tolerance: what Americans believe about civil liberties (New York, Russell Sage).

NARVAEZ, D. (1998) The influence of moral schemas on the reconstruction of moral narratives in eighth graders and college students, Fournal of Educational Psychology, 90, pp. 13-24.

NarvaeZ, D. (1999) Using discourse processing methods to study moral thinking, Educational Psychology Review, 11, pp. 377-394.

Narvaez, D., Bentley, J., Gleason, T. \& Samuels, S.J. (1998) Moral theme comprehension in third grade, fifth grade and college students, Reading Psychology, 19, pp. 217-241.

Narvaez, D., Gleason, T., Mitchell, C. \& Bentley, J. (1999) Moral theme comprehension in children, fournal of Educational Psychology, 91, pp. 477-487.

Narvaez, D. \& Rest, J. (1995) The four components of acting morally, in: W. Kurtines \& J. GewirtZ (Eds) Moral Behavior and Moral Development: an introduction, pp. 385-400 (New York, McGrawHill).

Nietzsche, F. (1986/1968) Beyond Good and Evil, W. Kaufman, (Trans.) The Portable Nietzsche, pp. 443-447 (New York, Viking Press).

NisbeTt, R.E. \& Wilson, T.D. (1977) Telling more than we can know: verbal reports on mental processes, Psychological Review, 84, pp. 231-259.

Nozick, R. (1974) Anarchy, State, and Utopia (New York, Basic Books).

RAwLs, J. (1971) A Theory of fustice (Cambridge, MA, Harvard Press).

Rawls, J. (1993) Political Liberalism (New York, Columbia University Press).

REED, D.R.C. (1997) Following Kohlberg: liberalism and the practice of the democratic community (Notre Dame, IN, University of Notre Dame Press).

Rest, J. (1983) Morality, in: P.H. Mussen (Series Ed.), J. Flavell \& E. Markman (Vol. Eds) Handbook of Child Psychology: vol 3, Cognitive Development, 4th edn, pp. 556-629 (New York, Wiley).

Rest, J., Mrtchell, C., Narvaez, D. \& Thoma, S.J. (2000) How test length affects the validity and reliability of the Defining Issues Test, manuscript submitted for publication.

Rest, J. \& Narvaez, D. (Eds) (1994) Moral Development in the Professions: psychology and applied ethics (Hillsdale, NJ, Lawrence Erlbaum).

Rest, J., Narvaez, D., Bebeau, M.J. \& Thoma, S.J. (1999) Postconventional Moral Thinking: a neoKohlbergian approach (Mahwah, NJ, Lawrence Erlbaum).

Rest, J., Narvaez, D., Mitchell, C. \& Thoma, S.J. (1999) Exploring Moral fudgment: a technical manual for the Defining Issues Test, manuscript available from Center, University of Minnesota. 
Rest, J., Narvaez, D., Thoma, S.J. \& Bebeau, M.J. (1999) DIT2: devising and testing a revised instrument of moral judgment, fournal of Educational Psychology, 91, pp. 644-659.

Rest, J., Thoma, S.J. \& NArvaez, D. (2000) Moral judgment: stages and schemas, manuscript submitted for publication.

Rest, J., Thoma, S.J., Narvaez, D. \& Bebeau, M.J. (1997) Alchemy and beyond: indexing the Defining Issues Test, fournal of Educational Psychology, 89, pp. 498-507.

Rummelhart, D.E. (1980) Schemata: the building blocks of cognition, in: R. SPINo, B. BRUCE \& W. BREWER (Eds) Theoretical Issues in Reading Comprehension, pp. 33-58 (Hillsdale, NJ, Erlbaum).

SANDEL, M. (1982) Liberalism and the Limits of Fustice (Cambridge, MA, Cambridge University Press).

SIEGLER, R.S. (1997) Concepts and methods for studying cognitive change, in: E. Amsel \& K.A. RENNinger (Eds) Change and Development: issues of theory, method, and application, pp. 77-98 (Mahwah, NJ, Lawrence Erlbaum).

Stevenson, C.L. (1937) The emotive meaning of ethical terms, Mind, XLVI, pp. 14-31.

TAYLOR, S.E. \& CROCKER, J. (1981) Schematic bases of social information processing, in: E.T. HigGINS, C.P. HERman \& M.P. ZANNA (Eds) Social Cognition: the Ontario Symposium, vol. 1, pp. 89-134 (Hillsdale, NJ, Erlbaum).

Тнома, S.J. (1986) Estimating gender differences in the comprehension and preference of moral issues, Developmental Review, 6, pp. 165-180.

Thoma, S.J. (1994) Moral judgment and moral action, in: J. Rest \& D. NARvaEz (Eds) Moral Development in the Professions: psychology and applied ethics, pp. 199-211 (Hillsdale, NJ, Erlbaum).

Thoma, S., Narvaez, D., Rest, J. \& Derryberry, P. (1999) The distinctiveness of moral judgment, Educational Psychology Review, 11, pp. 325-342.

Toulmin, S. (1981) The tyranny of principles, Hastings Center Report, 11, pp. 31-39.

TuRIEL, E. (1983) The Development of Social Knowledge; morality and convention (Cambridge, Cambridge University Press).

Uleman, J.S. \& Bargh, J.A. (1989) Unintended Thought (New York, Guilford Press).

WALZER, M. (1983) Spheres of Fustice (New York, Basic Books).

Youniss, J. \& Yates, M. (1997) Community Service and Social Responsibility in Youth (Chicago, University of Chicago Press). 